\title{
No Rupture Surface Sliding Geo-Technique in Deep Excavation for Static and Especially for Seismic Thrust
}

\author{
Ampeglio D. Garini \\ Consulting Engineer, Genoa 16044, Italy
}

\begin{abstract}
In the recent literature concerning the multi-propped bottom-up technique Shanghai Metro Stations Excavations, there is evidence of the importance of the disturbance in terms of greater wall horizontal deflections and consequently vertical settlements in the neighbouring, caused by the late long time of open -cut excavation without propping. Here is proposed, theoretical and pragmatic at the same time, a new approach to face the problem of the wall deflections and the related vertical settlements behind the wall. The solution proposed is indeed to impede any formation of the incipient sliding in the active wedge soil rupture surface, by oblique piling crossing over the rupture surface through a longer pile penetration length in relation to the active wedge before any excavation process starts. This piled-construction will then cut to shape the excavation profiles recurring to loss of piles material. This solution is particularly fit for high seismicity prone areas, because of the minor relative loss of per unit length of pile, caused by the greater depth of the rupture surfaces to get and cross over.
\end{abstract}

Key words: Active wedge, bottom-up technique, horizontal deflections, vertical excavation, vertical settlements, metro stations, flexible walls.

\section{Introduction}

\subsection{Evidence of the Intervention Technique} Time-Dependent Pit Wall Deflection

In Ref. [1], it is shown how four metro stations with similar supporting systems and pit geometries, excavated in Shanghai soft clay with different soil removal procedures and time support interventions entail correspondent different level of wall deflections and different vertical soil settlements in the neighborhood, i.e., the measured maximum wall deflections, the maximum ground settlements and the wall heaves at the lower bound so called poorly excavated Zhenbei Road Station was 2-5 times the corresponding values measured at the upper bound so called appropriately excavated Schangcheng Road Station.

Corresponding author: Ampeglio Diego Garini, master degree in civil engineering-transportation section, research fields: geomechanics and soil-structure interaction.

\subsection{Proposal for Radically Facing the Displacement} Field behind the Wall

Two phenomena contemporarily act during excavation in soft clayey soils, namely the failure rupture surface development due to the excavation procedures and a creep action in the excavated mass, as indicated in Ref. [1].

The typical stress path behavior in cohesive soils behind the wall, when the flexible wall horizontal deflection due to an active state of stress is not impeded, due to the formation of a negative excess pore pressure namely when $\Delta \sigma_{\mathrm{h}}<0$, is so as to provoke the most critical failure condition for the long term drained case.

On the contrary, in the embedded portion in front of the flexible wall, this is in general true only for OC clays as visible in Ref. [2].

A condition of active stress might be managed in order to limit the wall deflections, for multi-anchored flexible walls in multi layered soils as indicated in Ref. [3]. 
Here a technique is proposed aiming to stop the development of the Coulomb rupture surfaces, provoking a zero sliding situation and consequently the persistence of a $K_{0}$ condition during the excavations and after the wall construction.

The same conditions and solutions are generally valid for a general type of soil both only frictional and frictional and cohesive.

\section{Zero Rupture Surface Sliding Construction Technique}

\subsection{Construction Technique}

The construction technique of multi-anchored flexible walls, for a sketch thread like that shown in Fig. 1, must be simply conceived with the following construction phases:

(1) From the ground level drill battered secant steel micro piles with a slope so that they will be perpendicular to the Coulomb frictional rupture surface;

(2) From the ground level, along the vertical future excavation profile, drill vertical secant steel micro piles to intersect the gap left from the previously constructed battered piles;

(3) Excavate the shallow soil between the battered and the vertical piles;

(4) At the intersection level between secant and vertical piles, construct a wellded waler beam that joins the two series of piles;

(5) Cut the battered piles above the waler beam;

(6) From the new horizontal level of the constructed welded waler beam, construct a second series of battered steel micro piles exactly in the same way as for the first one for getting a deeper anchorage level along the vertical wall;

(7) Excavate the new shallow soil between the second battered piles and the vertical piles;

(8) Construct a second wellded waler beam that joins the two series of piles at this second level along the vertical wall;

(9) Cut the second battered piles above the second waler beam;

(10) Go on with the same construction sequence for any other third, fourth and so on, possible level of anchorages.

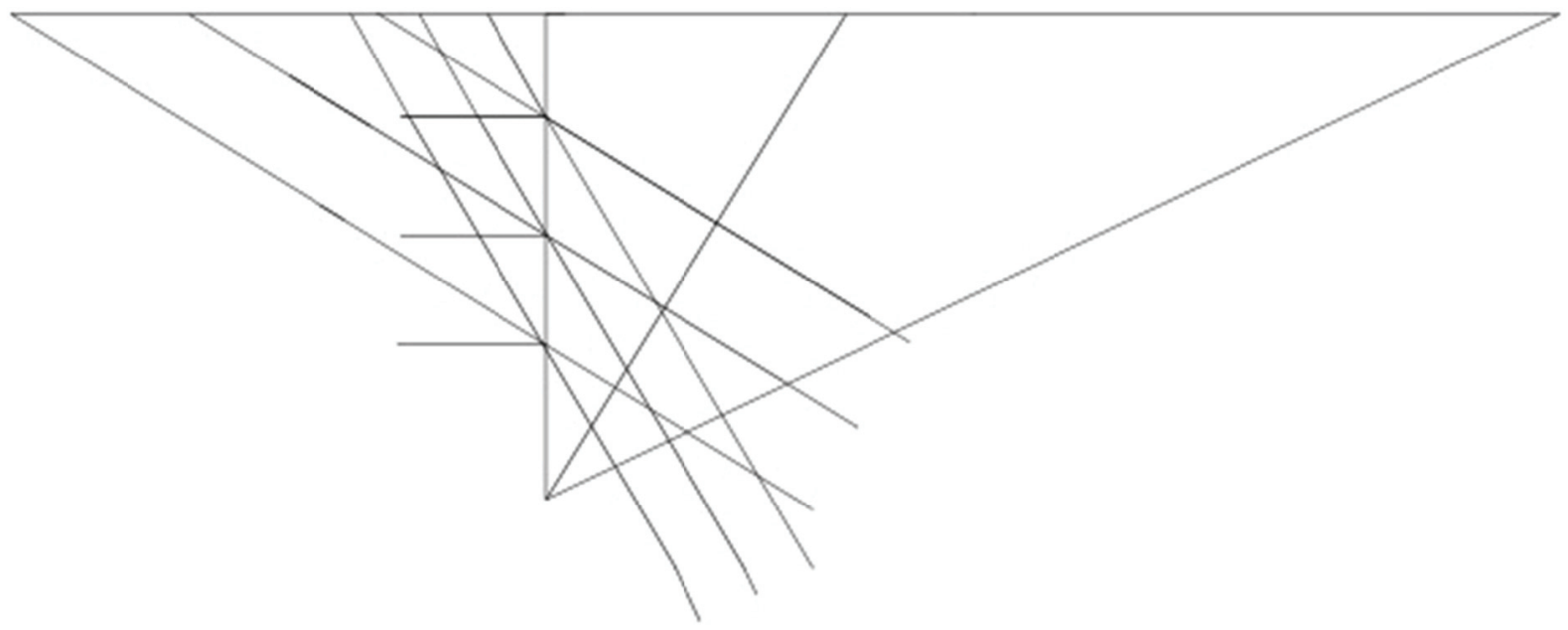

Fig. 1 Tie-back thread for a static and seismic thrust wedge. 


\subsection{Calculations Evaluations}

The technology here proposed may be figured out with a classical vertical wall Rankine scheme where we get:

$$
\begin{gathered}
T=\frac{\left(c_{1}+c_{2}\right) H}{\sin \left(\frac{\pi}{4}+\frac{\varphi^{\prime}}{2}\right)}+N \tan \left(\varphi^{\prime}\right) \\
N=W \cos \left(\frac{\pi}{4}+\frac{\varphi^{\prime}}{2}\right)+S_{A} \sin \left(\frac{\pi}{4}+\frac{\varphi^{\prime}}{2}\right) \\
S_{A}=\frac{0.5 \gamma H^{2}}{\left[\tan \left(\frac{\pi}{4}+\frac{\varphi^{\prime}}{2}\right]^{2}\right.}-\frac{2 c_{1} H}{\left[\tan \left(\frac{\pi}{4}+\frac{\varphi^{\prime}}{2}\right)\right]} \\
W=0.5 \gamma H^{2}\left[\operatorname{cotan}\left(\frac{\pi}{4}+\frac{\varphi^{\prime}}{2}\right)\right] \\
T_{C}=-\frac{2 c_{2} H}{\left[\tan \left(\frac{\pi}{4}+\frac{\varphi^{\prime}}{2}\right]\right.}
\end{gathered}
$$

where $T$ is the soil resistance along the rupture surface, $N$ is the corresponding normal force, $S_{A}$ is the active thrust, $T_{C}$ is the technological added back thrust, $c_{1}, \varphi$ ' are the mechanical characteristic of the excavated homogeneous soil, $H$ is the depth of excavation, $\gamma$ is the soil unit weight and $c_{2}$ is the technologically additional cohesion due to the battered piles.

In this way, the battered piles provide the additional cohesion $c_{2}$, and the related additional resistance $T_{C}$, capable to stop both failure along the rupture surface and any creep phenomenon, this latter caused by the absence of the active thrust in the pushing wedge.

\section{Discussion}

\subsection{General Validity of the Technological Solution}

The general validity of this technological solution is supported on crossing over with abundant additional battered pile length, the potential retaining wall rupture surfaces, in order to keep a $K_{0}$ condition in the potentially thrusting soil.

\subsection{Advantage of the Solution in Seismic Strong Motion Prone Areas}

As known the seismic Mononobe-Okabe solution considers rupture surfaces with reduced angles with the horizontal plane and for this reason the cutting length of the battered piles as in steps 5 and 9 of the above said construction sequence, will be, as visible in Fig. 1, far more relatively less compared to a static retaining wall solution.

\section{Conclusions}

A construction procedure was proposed to envisage a method to limit and even stop lateral deflections and vertical settlements in multi-anchored and multi-propped vertical flexible walls, with particular emphasis to the use of steel micro piles.

The methodology utilizes the added cohesion $c_{2}$ due to battered steel micro piles perpendicular to the retaining wall potential rupture surfaces, in order to impede the start of shear rupture along the classical potential rupture surface and keep a $K_{0}$ condition and do not provoke any creep phenomenon.

The proposed procedure recurs to the use of secant battered piles each vertical secant piles gap, to cut the inclined external part of the battered piles outside the vertical wall after the excavation of the shallow soil is made, and the waler beam at the vertical wall anchorage level is welded to vertical piles.

Due to typical geometry of the Mononobe-Okaba seismic rupture surface, the loss of cut steel piles will be relatively less than that in the static case, where also this procedure could be applicable, but not with the same great advantageous spare of steel material as for the seismic case.

\section{References}

[1] Tan, Y., Wei, B., and Yanping, D. 2015. "Lessons Learned from Construction of Shanghai Metro Stations: Importance of Quick Excavation, Prompt Propping, 


\section{Static and Especially for Seismic Thrust}

Timely Casting, and Segmented Construction." Journal Perform. Constr. Facil. 29 (4): 04014096.

[2] Lancellotta, R. 1993. Geotecnica. Bologna, Italy: Zanichelli. (in Italian)
[3] Garini, A. D. 2008. "An Analytical Calculation of Multianchored Walls and Some Consequences." In Proceedings of the Second British Geotechnical Association International Conference on Foundations, 687-91. 